\title{
Palma y la construcción de la identidad nacional
}

Por Eduardo Huárag Álvarez 
Profesor asociado del departamento de Humanidades de la Pontificia Universidad Católica del Perú. Ha sido profesor visitante en la Universidad de Burdeos y en la Universidad de Munich. Ha publicado libros de literatura latinoamericana relacionados con el pensamiento mítico. 
El contexto social y cultural de fines del siglo XVIII e inicios del XIX nos muestra una región en la que, progresivamente, se internalizan las ideas de libertad y soberanía que se difundieron desde Francia, antes y después de la revolución. Si bien los afanes de independencia permitieron la apertura y desarrollo de un repertorio temático relacionado con la libertad y la independencia, lo cierto es que desde la perspectiva de la creación literaria, los manifiestos que se elaboran y difunden no hacen sino seguir los preceptos y tendencias literarias neoclásicas a imitación de lo que se cultivaba en España. Con la independencia no hay variaciones en la literatura.

La república incipiente se abre camino en medio de cerradas discusiones políticas, caudillismos y una fuerte crisis económica. No parece haber un clima favorable para el desarrollo de una alternativa cultural propia, pese al sentimiento americanista. Piénsese en Andrés Bello y las Odas de Joaquín Olmedo, que revelaron su sentimiento americanista, pero fueron escritas bajo los preceptos del neoclasicismo.

En la segunda década del siglo XIX, el romanticismo europeo permitió el desarrollo de la lírica sentimental, intensamente apasionada, pero también la novela histórica y los relatos costumbristas. En algunos casos, como en la literatura alemana, se optó por una literatura reflexiva. En América se cultivó un costumbrismo fundamentalmente anecdótico o de descripción de hechos particulares que de algún modo iban configurando la identidad americana. 
La descripción de lo propio se asume como rasgo que puede identificar lo particular de América, por eso se difunden costumbres, hechos episódicos peculiares, folclóricos o rasgos de su geografía. Lo importante era destacar lo americano. Y el medio que se utilizó para trasmitir tales mensajes no fueron necesariamente relatos literarios. El periodismo y la crónica cobran un inusitado interés entre los intelectuales. A los cronistas o intelectuales que incursionaban en la escritura o relato de costumbres parece que les bastaba la idea de que se escribiera sobre algo propio de América y poco se esforzaron por ahondar en sus reflexiones o convertir en texto un producto que verdaderamente llamase la atención por sus virtudes literarias. Quizá por eso, Jorge Cornejo Polar considera que los costumbristas:

“(...) no calan muy hondo, no pasan de lo circundante, para usar la expresión del ensayista venezolano (tal vez era imposible que en ese momento lo hicieran). No se preguntan por las causas de aquello que describen o critican, ni indagan por los problemas subyacentes a la superficie social, que es lo que principalmente les atrae y examinan" (Cornejo Polar, Jorge: 2001: 19)

El costumbrismo que se cultiva en el Perú, en líneas generales, sigue los modelos establecidos por escritores españoles como Mesonero Romanos y Mariano José de Larra. El público acogió el estilo porque: “(...) veía en ellos una versión graciosa del ambiente que le era familiar y conocido" (Correa Calderón, E.: 1951: XXXII) Aunque el costumbrismo español sigue una larga tradición que se puede remontar al mismo siglo XVIII, lo importante es que en el siglo XIX toma algunos rasgos del romanticismo, por ejemplo, el gusto por evocar hechos pasados: “(...) suspiran por todo aquello que está distante en el tiempo y en el espacio..."(Correa Calderón, E.: 195 l:LXVI). El escritor costumbrista, pese a asumir algunas 
características del romanticismo, no cae en el sentimentalismo ni el apasionamiento. Frente a los neoclásicos y románticos, el costumbrista es un realista: “(...) toma de la vida misma los elementos de su arte, sin que se le ocurra apelar a la fantasía y a la deformación como recurso." (Correa Calderón, E.: 1951: LXVIII). Los costumbristas, de modo explícito, o encubierto, no dejan de manifestar que sus comentarios tienen un propósito moral. Su crítica social suele terminar en un tono irónico o un humor melancólico.

Como muestra de los textos del costumbrismo español, revisemos un texto de Mesonero y otro de Larra. En el relato "El periodista", se señala que se trata de una profesión que ha venido con los tiempos modernos. El periodista no trae muchos títulos y sin embargo tiene mucho poder. Agrega que se trata de un profesional que “(...) habla con desenfado de cualquier asunto, que emprende todas las carreras y ninguna concluye, que critica todos los libros sin abrir uno jamás" (Correa Calderón, E.:1951: 1289). El periodista tiene vínculos con los gobernantes y debido a su desenfado es capaz de alternar con personajes de distinto rango social. Entre los rasgos de este profesional se señala que "(...) decide las cuestiones palpitantes, anatomiza a los hombres del poder, conmueve las masas, forma la opinión, es representante del pueblo" (Correa Calderón, E.: 195 1: 1290).

Larra, a su vez, hace un motivo de su relato cierta frase que tiene arraigo en los usos de la colectividad. Esta misma actitud asumieron los costumbristas en Latinoamérica que con frecuencia recurrían a los refranes y los decires. Larra se quiere referir a "En este país" y construye un relato ficcional que se centra en las diferentes situaciones en los que aparecerá la frase. Señala Larra: "En este país... es la frase que todos repetimos a porfía, frase que sirve de clave para toda clase de explicaciones cualquiera que sea la cosa que a nuestros ojos choque en mal 
sentido" (Correa Calderón, E.: 1951: 892). Ahora veamos los diferentes momentos en que se usa la frase en el relato:

- Amigo, en este país no se puede dar un almuerzo a nadie; hay que recurrir a los platos comunes y al chocolate" (p.894).

- iCosas de España!- me salió diciendo, al referirme su desgracia” (p. 894).

- iLo ve usted, Fígaro - me dijo - lo ve usted? En este país no se puede escribir. En España no se puede escribir. En París hubiera vendido diez ediciones. (p.894).

- iEn este país no hay más que miseria! - exclamaba, horripilado" (p. 895).

Y como dijimos, en muchos casos los costumbristas españoles terminan dándole un sentido moralista o educativo al hecho anecdótico:

"Borremos, pues, de nuestro lenguaje la humillante expresión que no nombra a este país sino para denigrarlo, volvamos los ojos atrás, comparemos, y nos creeremos felices." (Correa Calderón, E.: 1951: 895).

El costumbrismo en el Perú se centra mucho en el hecho episódico, no ahonda en el escenario o fines trascendentes. Les atrae las peculiaridades que pueden advertir en algunos personajes o costumbres de larga tradición. Recordemos algunos relatos de esa época: "El paseo de Amancaes" "Un viaje" (de Pardo y Aliaga); y "Los carnavales", "Las calles de Lima", "El té y la mazamorra", de Manuel Ascencio Segura. Tales escritos tenían cierta gracia e inconfundible humor y ello, probablemente, era suficiente para la satisfacción de los lectores 
de aquel escenario nacional. Lo cierto es que se escribía para los lectores locales, se esperaba, quizá, que valoren lo suyo, lo propio. La pequeña historia carecía de perspectiva. El referente era el ámbito local y no esperaba trascender. Por otro lado, los escritores no planteaban una trama en la que se pueda apreciar una perspectiva histórica. Eran historias encapsuladas en su cotidianeidad. Y sin embargo, se vivía un momento significativo: la nación republicana acababa de instalarse. Y hasta el hecho mismo de las luchas internas por el poder podían ser motivo de reflexión más honda y trascendente. El periodismo y la cultura popular utilizan la caricatura para satirizar a personajes controvertidos y a ello se dedicaba el ingenio y la creatividad. Coincidimos con Antonio Cornejo Polar quien sostiene que lo que caracteriza al costumbrismo es:

\begin{abstract}
“(...) su apego a la realidad más inmediata, percibida casi siempre en sus estratos epidérmicos; su tono humorístico satírico que puede ser burla inocua o arma de lucha ideológica y política". (Cornejo Polar, A.: 1980: Tomo VIII: 18).
\end{abstract}

En la segunda parte del siglo XIX recién se puede avizorar una actitud verdaderamente innovadora. Con los mismos temas y acaso los mismos recursos del costumbrismo, Palma se propone -quizá sin ser muy consciente de ello- una necesaria mirada al pasado para no perder continuidad en nuestra tradición cultural. No olvidemos, sin embargo, que una de las características del romanticismo era la evocación de hechos que se produjeron en el pasado, acontecimientos de gran trascendencia o que el romántico encontraba relevante. Así es como nace la novela histórica. Palma hereda de la tradición europea ese gusto por la evocación de la historia pasada. En sus tradiciones peruanas, sus personajes y acontecimientos son parte de la historia virreinal o republicana, y el narrador se esmera en insertar un parrafillo histórico -como él mismo le llamaba- 
con el propósito de darle mayor autenticidad, no importa que sus datos históricos no fueran del todo precisos. Pero si bien las tradiciones peruanas aparecen enlazadas a esa tendencia de recrear acontecimientos y personajes del pasado que trajo el gusto romántico europeo, Palma tiene una particularidad que lo hace singular: ese necesario vínculo a la tradición oral, a la cultura popular. Lo que enriquece significativamente sus relatos es esa explicación de cómo imaginó el pueblo, en sus decires y refranes, los acontecimientos históricos. De esa manera, Palma aporta la mirada desde la cultura popular, una mirada que es distinta a la que se encontraba en la historia formal e institucional.

Palma pretende una mirada distinta de la historia nacional. Considera que aunque era necesaria la instalación de una república independiente, no se puede ignorar la herencia cultural que dejaron los españoles. Los conquistadores y personajes del escenario virreinal murieron, pero dejaron sus costumbres, sus creencias, su modo de actuar. Y la república era heredera, queriéndolo o no, de esa idiosincrasia que habían hecho suyos los criollos y los mestizos. Palma explica:

"Allá en los remotos días de mi juventud, a más de un tercio de siglo, ocurrióme pensar que era hasta obra de patriotismo popularizar los recuerdos del pasado, y que tal fruto no podía obtenerse empleando el estilo severo del historiador, estilo que hace bostezar a los indoctos" (Palma, R. En Cachivaches, p. 140; citado en "Tiempos de infancia y bohemia. Ricardo Palma”, Oswaldo Holguín, Lima, Fondo editorial PUCP, 1994, p. 179).

Palma estuvo muy identificado con la Lima criolla, capitalina. Sin embargo, ello no le impidió abordar temas con personajes del mundo andino. Precisamente, porque al abordar temas históricos se encontró con personajes y acontecimientos de la 
serranía del país. Uno de esos relatos es "Los malditos" en el que alude a cierto incidente con los indios de Sisicaya o San Pedro Mama. Los hechos se remontan a 1601. Se menciona que en aquel entonces los nativos seguían haciendo sus rituales y ceremonias a sus dioses ancestrales que los españolas consideraban hechos de herejía. Según el relato:

\begin{abstract}
“(...) informados el virrey Velazco y el arzobispo Santo Toribio de que los cuatro mil indios de Sisicaya profesaban la misma idolatría, resolvieron emplear cinco misioneros para que ayudasen al cura en la conquista de almas. Concertados los naturales sorprendieron una noche al cura y lo mataron a azotes" (Palma, R.: 1968: 238)
\end{abstract}

En sus tradiciones, Palma refiere incidentes que revelan la reacción de los nativos ante las injusticias de las autoridades españolas. Uno de los personajes más importantes de esa gesta emancipadora fue Túpac Amaru. Palma, tan ligado a la cultura oral, no podía dejar de lado los pasquines como expresión popular. El título de una de sus tradiciones, precisamente, se llama: "Los pasquines de Yauli" y el incidente que se narra ocurrió en 1780. Se alude a una invocación para que los aldeanos fueran a Canta donde se les habilitaría armas para sumarse a la rebelión de Túpac Amaru.

El mismo acto de rebeldía lo volveremos a encontrar en "Los brujos de Shulcahuanga". Aquí también se menciona los pasquines que aparecieron en Huamachuco, Uzquil, Cajabamba, Otuzco y otros pueblos. ¿Qué ilustraban los pasquines?: "En grosero lenguaje se ponía de oro y azul a Fernando VII y en caricatura se le representaba de hinojos ante Túpac Amaru" (Palma, R.: 1968: 932).

Es decir, la misma idea de inversión del orden que subyace en el Inkarri, esa mentalidad mesiánica que aspira a un cambio 
de la sociedad, de la historia que había sido desfavorable para los nativos indígenas. Por cierto, en la época en que escribe Palma no se habían hechos estudios acerca de esa mentalidad mesiánica ni se sabía de la difusión del mito de Inkarri en la zona andina.

Palma gusta de la historia y siente necesidad de reconstruir el escenario en el que llevan su vida cotidiana los pobladores. Los vecinos de entonces se sentían de la nobleza debido a sus títulos nobiliarios. Existía, asimismo, una jerarquización social. Los españoles trasladaron sus códigos sociales al virreinato. Perú y México eran una prolongación de España y sus costumbres. Las medievales costumbres sociales parecían ancladas en el tiempo y en el virreinato. El prestigio y la valoración dependían de los títulos que poseía un individuo.

A propósito de ello, recordemos el relato "Un litigio original". Se refiere a un incidente aparentemente sencillo. En ese año de 1698, dos carruajes conducidos por sus cocheros se encuentran en una esquina y ninguno le quiere ceder el paso al otro. Los amos, al ver por qué se habían detenido, ordenan: "No cedas, negro, porque te mato a latigazos" (Palma: 1968:489). Y como para que tengamos una idea de los personajes que vivían en la Lima virreinal de entonces, el narrador consigna a los notables y sus títulos nobiliarios. Todos ellos eran parte de una aristocracia que se congregó en la iglesia de San Agustín para la fiesta de la Natividad de la Virgen.

Esta vez, el enfrentamiento era entre don Dionisio Pérez Manrique y Villagrán; y de otro lado, el primer conde de Sierrabella, don Cristóbal Mesía y Valenzuela. El narrador especifica que la guerra era “(...) de casa a casa; asunto de pergaminos más o menos amarillentos, y de un arminio, roel y dragante de más o menos el escudo de armas" (Palma, R.:1968: 488). 
Como no tenían trazas de ceder, un vizconde sugiere que fueran ante el virrey. Este, que tenía amigos entre uno y otro bando, prefirió que sea su majestad el rey quien resolviera el litigio. Se trataba de un asunto de honor. De modo que los litigantes se esmeraron en acreditar ante la corte “(..) representantes letrados y reyes de armas que tuvieran la heráldica en la punta de los dedos, y se gastaron un dineral en el proceso" (Palma, R.: 1968: 495). Esto se realiza por la importancia del honor, aun cuando el producto de la querella no tuviera el costo del proceso judicial. Así eran esos tiempos, y ese afán de querellar por hechos absurdos. El honor no tenía precio. Significaba el prestigio social del querellante y su familia. Y este sería una de las herencias en las costumbres del Perú republicano. Nos independizamos del dominio español, pero la costumbre de querellar o los litigios de honor se mantuvieron. No extrañe que, en muchos casos, los juicios se prolongaran por años y que fueran heredados por los descendientes.

En el caso que refiere el relato, el juicio demoró dos años. Cuando se conoció la sentencia, no quedaba nada de los coches: “(...) no existía ya ni un clavo de los coches; porque, estando los vehículos tanto tiempo en la vía pública y a la intemperie, no hubo transeúnte que no se creyera autorizado para llevarse siquiera una rueda" (Palma, R.: 1968: 496). Este desenlace muestra el absurdo de las querellas y cómo es que una aristocracia vivía en función de sus títulos nobiliarios y una jerarquización a la que se aferraban porque de ello dependía su prestigio social. Esta costumbre de las querellas por cualquier hecho insignificante es una costumbre que aún se mantiene en muchos lugares del país. No se plantea como enfrentamiento de títulos nobiliarios, pero el asunto del honor es el mismo.

En el relato "Con días y ollas venceremos", se comenta que, en los albores de la independencia (junio de 1821), a don José de San Martín -acantonado en Huaura- se le ocurrió utilizar los 
servicios de un alfarero para “(...) fabricar una olla con doble fondo, tan diestramente preparada que el ojo más experto no pudiera descubrir la trampa" (Palma, R.: 1968: 959). El encargado de llevar el mensaje patriota iba por la calle gritando “iOllas y platos! iBaratos! iBaratos!” (Palma, R.: 1968: 960) $\mathrm{Y}$ al instante salía el designado para recibir el mensaje. Lo importante es que el narrador aprovecha el hecho anecdótico para señalar que en esos tiempos las horas estaban establecidas por los pregoneros de modo que: "Casas había en que para saber la hora no se consultaba reloj, sino el pregón de los vendedores ambulantes" (Palma, R.: 1968: 980). Y es que la tradición y la costumbre habían establecido una regularidad en la presencia de los pregones:

"La lechera indicaba las seis de la mañana.

La tisanera y la chichera de Terranova daban su pregón a las siete en punto.

El bizcochero y la vendedora de leche-vinagre, que gritaba ia la cuajadita! Designaban las ocho, ni un minuto más ni un minuto menos.

La vendedora de zanguito de ñajú y choncholíes marcaba las cuatro, hora de canónigos.

La tamalera era anuncio de las diez.

A las once pasaban la melonera y la mulata del convento vendiendo ranfañote, cocada, bocado de rey, chancaquitas de cancha y de maní, y frejoles colados.

A las doce aparecían el frutero de canasta llena y el proveedor de empanaditas de picadillo.

A la una era indefectiblemente señalada por el vendedor de ante con ante, la arrocera y el alfajorero.

A las dos de la tarde la picaronera, el humitero y el de la rica causa de Trujillo atronaban con sus pregones.

A las tres el melcochero, la turronera y el anticuchero o vendedor de bisteque en palito clamoreaban con más puntualidad que la Mari-Angola de la catedral. 
A las cuatro gritaban la picantera y el de la piñita de nuez.

A las cinco chillaban el jazminero, el de las caramanducas y el vendedor de flores de trapo, que gritaba: iJardín, jardín! ¿Muchacha, no hueles?

A las seis canturreaban el raicero y el galletero.

A las siete de la noche pregonaban el caramelero, la mazamorrera y la champucera.

A las ocho el heladero y el barquillero".

(Palma, R.: 1968: 960).

Con esta detallada referencia de los pregoneros de cada hora es posible imaginar las costumbres de una Lima que, a pesar de los títulos nobiliarios de su aristocracia, no podía desentenderse de las costumbres. La idiosincrasia de la nación, de esta manera, se fue configurando con esa larga tradición que dejaron los españoles, pero con las costumbres nativas en esa fusión de razas mestizas, indígenas y negras, que es el Perú.

En el relato titulado "Las cortinas", Palma menciona que era parte de una costumbre de Lima: "Eso de adornar puertas y balcones con cortinas, cuando ha de pasar la procesión por una calle, es costumbre... ivamos!, se me atraganta e indigesta" (Palma, R.: 1968: 1436). Según refiere el narrador:

"En la época colonial, ciertas casas aristocráticas de Lima ostentaban cortinaje de terciopelo de Flandes recamado de oro. Pero ya se sabía que este adorno no tenía otro uso y que, concluida la fiesta, se guardaba hasta la inmediata. No es, pues, esta cortina la de mi crítica". (Palma, R.: 1968: 1436).

Sucede que, en algún momento, los sectores populares -que no podían adquirir terciopelo de Flandes- empezaron a usar como cortina, colchas y cubrecamas que usaban en sus dormitorios. Y 
eso es lo que al narrador no le parece apropiado: “(...) la prenda precisamente es de lo más irrespetuoso que cabe, porque trae consigo recuerdos de dormitorio que no siempre son pulcros ni castos" (Palma, R.: 1968: 1436). Aquí, pues, la costumbre seguramente difundida y practicada por la aristocracia entra en conflicto con los sectores populares que no pueden exhibir cortinas de Flandes. Es el gusto y lo pertinente lo que le hace rechazar, al narrador, las cortinas hechas de cubrecamas o sábanas.

En el relato "Los padrinos" revela cómo es que ciertas costumbres arraigaron de tal modo que hasta distorsionaron el sentido de justicia. Contar con padrinos es necesario, según el canon social establecido. Incluso, se sabe, que no se podría acceder a ciertos cargos si no se cuenta con padrinos. La función del padrino se ha convertido en norma social. Para aspirar justicia en alguna gestión era necesario tener padrino: “'Tiene usted en el Congreso una pretensión más justa que justicia? Pues es usted moro al agua si no se agarra de buena aldaba, vulgo padrino" (Palma, R.: 1968: 1441).

Con el padrinazgo el ahijado se aseguraba la obtención de facilidades para ocupar un cargo o ejercer una función pública. Se podría tener méritos pero si no se tenía padrino, el aspirante tenía todas las de perder. Y cuando ambos tenían padrino, prevalecía aquel cuyo padrino era de mayor jerarquía o rango social: "Sea usted hombre de méritos y aptitudes y láncese a pretender un puesto del Estado. Si no tiene más padrino que ésos, se quedará a chicha fresca" (Palma, R.: 1968: 1441). Es una herencia tergiversada y que el narrador no repara en revelar:

"Tenga usted un litigio en que rebose por su parte el buen derecho, y échese a roncar. Y verá usted que, aunque su contrario no tenga ni pizca de justicia, con tal que cuente con padrino o madrina de olor, color y sabor, que para el 
caso da lo mismo, le salen a usted los jueces con alguna triquiñuela que no estaba en su libro, y lo parten por el eje, y lo divierte" (Palma, R.: 1968: 1442).

El padrinazgo ha terminado siendo una institución del que no se podían desligar los ciudadanos de diferentes instancias sociales. Heredamos, pues, modos de ser y conductas que los españoles trajeron de Europa y que con el paso de los años fueron parte del escenario social y las costumbres de la República. La tarea que se propuso Palma es la configuración de esa cultura mestiza, enraizada en la oralidad. Para Palma la identidad nacional era una confluencia de razas, costumbres y modos de interpretar la realidad.

Otro aspecto a destacar y que es tal vez la razón para que los lectores de los sectores populares se identifiquen con él, es el enlace que tienen sus relatos con la cultura oral. Palma no es apergaminado, no le gusta el formalismo academicista. Palma recurre a los refranes, la memoria popular y las costumbres tradicionales. Por eso, encontraremos frases que en su época estaban en el habla de la cultura popular. Leamos algunas de dichas frases: "Comida acabada, amistad terminada", "Las hechas y por hacer", "Una cosa es quebrar huevos y otra cosa es hacer tortilla", "La cuerda se rompe por el lado más delgado".

Palma manifiesta muchas veces que lo único que hace es comunicar lo conocido por el pueblo. Y cuando se dice que es conocido, se da a entender que se fundamenta en la cultura oral, aquello a lo que la historia institucionalizada otorga poco valor.

Finalmente, digamos que como los importantes innovadores Palma no parte de la nada ni refunda un modo distinto de contar. Palma se inscribe en esa larga tradición de costumbristas, en ese humor frecuente en los escritos limeños. Pero a diferencia de los costumbristas, Palma narra siendo consciente que debe 
presentar una trama argumental. El texto no podía ser una simple descripción o un alegato. Incluso, en su afán de veracidad, no deja de incluir su parrafillo histórico. Palma es heredero de esa tendencia que cultivó la narrativa histórica, aunque nuestro escritor cultiva un formato muy peculiar al que denominó tradiciones.

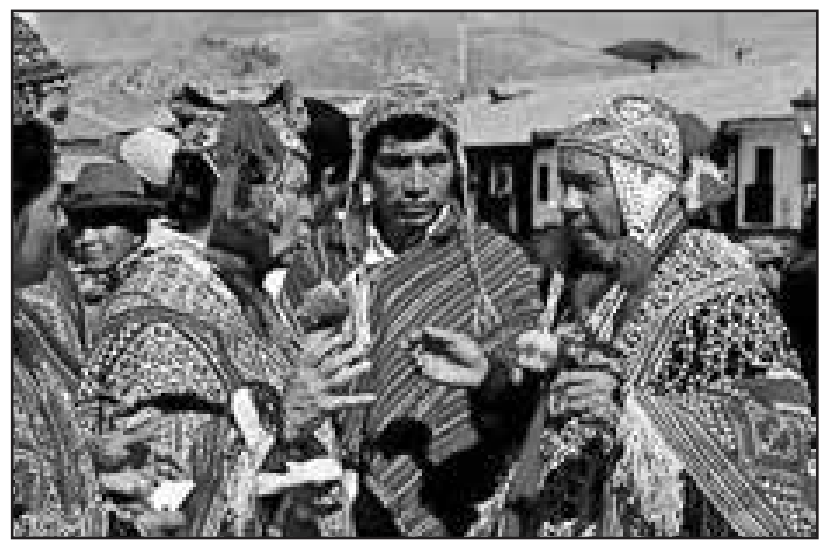

\section{Bibliografía}

CORNEJO POLAR, Antonio. Literatura en el Perú republicano, Lima, edición de Juan Mejía Baca, 1980. Tomo VIII.

CORNEJO POLAR, Jorge. El costumbrismo en el Perú, Lima, ediciones Copé, 2001.

CORREA CALDERÓN, E. Introducción al estudio del costumbrismo español" en "Costumbristas españoles, Madrid, ediciones Aguilar, 1951.

HOLGUÍN, Oswaldo. Tiempos de infancia y bohemia, Lima, Fondo editorial de la PUCP, 1994.

PALMA, Ricardo. Tradiciones Peruanas Completas, Madrid, Ediciones Aguilar, 1968. 